\title{
RANGE EXTENDER
}

\section{Liebe Leserin, lieber Leser,}

kürzlich lud das Deutsche Zentrum für Luft- und Raumfahrt (DLR) nach Stuttgart. Der Anlass war die Präsentation eines Freikolbenlineargenerators, kurz FKLG. Wie der Namen schon sagt, umfasst die Innovation einen Freikolbenmotor, an dem ein Lineargenerator angeschlossen ist. Die findigen Forscher des DLR wollen das Konzept künftig als Range Extender für Elektrofahrzeuge einsetzen. Dabei unterscheidet sich der Ansatz des DLR nicht nur konstruktiv von anderen Range Extendern, die derzeit entwickelt werden. Auch bei der Auslegung geht das DLR eigene Wege: Bislang waren Range Extender - jedenfalls solange sie keinen direkten mechanischen Durchtrieb zu den Antriebsrädern haben - zumeist als preiswerte und einfache Reichweitenverlängerer konzipiert, die auf einen schmalen Betriebsbereich optimiert sind.

Der FKLG demgegenüber ist ein HighTech-Produkt mit Direkteinspritzung und vollvariablem Ventiltrieb, bei dem sich das Verdichtungsverhältnis, die Kolbengeschwindigkeit und der Hubraum flexibel einstellen lassen. Durch seine variablen Eigenschaften lässt sich der Range Extender je nach Geschwindigkeit und Fahrverhalten auf die optimale Betriebsstrategie ausrichten, sprich der Betriebspunkt des Motors kann so eingestellt werden, dass das Fahrzeug möglichst effizient und umweltfreundlich unterwegs ist. Überlegungen des DLR sehen daher auch ein Antriebssystem mit einem relativ kleinen Akkumulator vor, der nur 50 km Aktionsradius ermöglichen soll. Darüber hinausgehende Reichweiten sollen vom FKLG abgedeckt werden. Durch den hohen verbrennungsmotorischen Wirkungsgrad in weiten Betriebsbereichen plant das DLR sogar, den
Akkumulator als Puffer zu umgehen und die elektrische Antriebsmaschine direkt mit der Energie aus dem FKLG zu versorgen. Wie ich finde ein mutiger Ansatz. Und es wird spannend sein zu sehen, welches Range-Extender-Konzept künftig das Rennen machen wird. Wer nun mehr über den FKLG des DLR wissen möchte, muss sich bis zur MTZ 10 gedulden. Dort stellen wir das System detailliert vor. Sicherlich werden Sie jedoch auch die Fachbeiträge der aktuellen Ausgabe interessieren. Das Titelthema etwa umfasst den Bereich Gemischbildung und Verbrennung. Nicht ohne Grund gilt er nach wie vor als ein Schlüssel auf dem Weg zu effizienteren und saubereren Verbrennungsmotoren - ob nun mit Kurbeltrieb oder mit Freikolben.

Herzlichst, Ihr

Richad Bacllaus

\section{RICHARD BACKHAUS,}

Stellvertretender Chefredakteur Wiesbaden, 7. März 2013

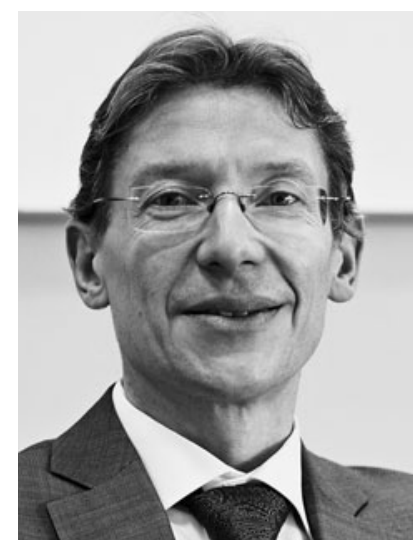

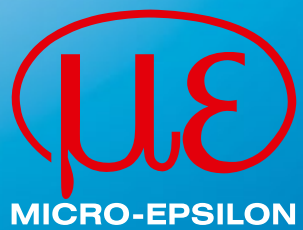

MICRO-EPSILON

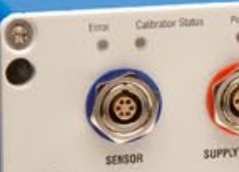

()) snecis snc our (2) (1)

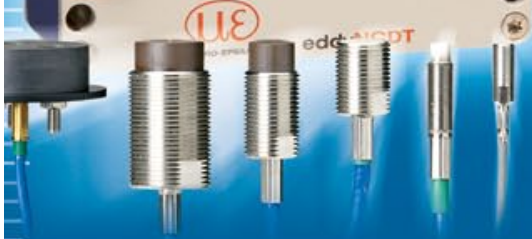

TECHNOLOGESPRUNG BE WIBBELSTROMWEASENSOREN

Die neuen Sensorsysteme eddyNCDT 3100 bieten mehr Präzision \& höheren Bedienkomfort durch:

- Intelligente Kombination von Analogund Digitaltechnik

- Sensoren tauschbar ohne Neuabgleich

- Webbrowser basierte Bedienung über PC

- Ethernet-Schnittstelle

- Messbereiche 0,5 mm - 15 mm

- Sensoren IP67 mit hochflexiblem Kabel

- Controller (Metallgehäuse IP65) für Hutschienen und Schraubmontage

www.micro-epsilon.de 